\title{
Additive Manufacturing for Future Facades: \\ The potential of 3D printed parts for the building envelope
}

\author{
Holger Strauß $\aleph^{a, b, *}$, Emmer Pfenninger Partner AG $^{a}$ and Ulrich Knaack ${ }^{b}$ \\ ${ }^{a}$ Specialist facade engineers and consultants, Münchenstein, Switzerland \\ ${ }^{\mathrm{b}}$ Faculty of Architecture, Facade Research Group, Delft University of Technology, Netherlands
}

\begin{abstract}
The basic principle of '3D Printing' is the layer wise production of real parts from virtual data - be it with laser, with power glue, electron beam or UV light processing (Hopkinson, Hague, \& Dickens, 2006). The professional application of '3D Printing' is 'Additive Manufacturing' (AM) and this opens a fascinating new world of engineering. It offers a selection of reliable building construction materials - done in concrete, aluminium, steel, high performance plastics or glass (Woodcock, 2011). No matter what applications can be found: to 'design for function', rather to 'design for production' turns our way of engineering of the last century upside down. As a result, AM opens the outlook to applications in our (built) future in combination with the available technologies of today (Strauß, 2013). The tool-less production with AM allows for new shapes and functional parts in small batch sizes - down to batch size one. The parts performance can be re-interpreted based on the demands within the system, not based on the limitations of conventional manufacturing. AM offers new ways of materializing the physical part around its function. Advancements can for example be achieved in the semi-finished goods: fittings with less, but higher integrated parts could offer a better performance with lower material consumption. Solving the most critical part of a free-form structure and allowing for a smart combination with the approved standards has a great potential, as well. It leads toward customized and enhanced performance. This paper discusses the possible changes and influences those emerging technologies have on the development of building envelopes. To achieve today's demands of future envelopes, we have to find new solutions. Additive Manufacturing is one possible way to do so.
\end{abstract}

Keywords: Architecture, facade engineering, 3D printing, Additive Manufacturing, bespoke building envelopes, future facades, innovation, performance, file to factory

\section{Introduction}

Since 1987 'Rapid Prototyping' (RP) is known as one fast way to materialise concept design ideas in a handy, digital way. By transferring 3D model data into physical parts in various available materials, it is an accepted tool in a broad range of disciplines. Limitations in building chamber size, and therefore limited part sizes, firstly brought up applications in fields where larger components were not necessarily needed: scaled models, medical implants, jewellery, or even casting moulds of engine parts as semi finished goods, are a few examples. And it was in those fields of application, where Rapid Prototyping grew during its first two decades of being. From RP also derived other kinds of applications: 'Rapid Tooling' (RT), which, in industrial mass production has changed the manner of how production tools are made, as well as 'Rapid Manufacturing' (RM) which is specifically

\footnotetext{
${ }^{*}$ Corresponding author: Holger Strauß, Emmer Pfenninger Partner AG, Weidenstrasse 13, 4142 Münchenstein, Switzerland. Technical University Delft, Facade Research Group. E-mail: strauss.planen@yahoo.de.
} 
designed for the production of finished products that are immediately usable without the need for subsequent production steps (Hopkinson et al., 2006). All available additive processes are based on a few underlying principles of layer wise production, where materials are added onto each other and a part is built up layer by layer (see Fig. 1). Additive Fabrication is clearly separated from the conventional production principles, such as subtractive manufacturing, where material is taken away from the raw material by cutting, grinding, milling, etc., or formative production processes, where raw material is shaped in moulds and forms with injection moulding, deep-drawing and bending.

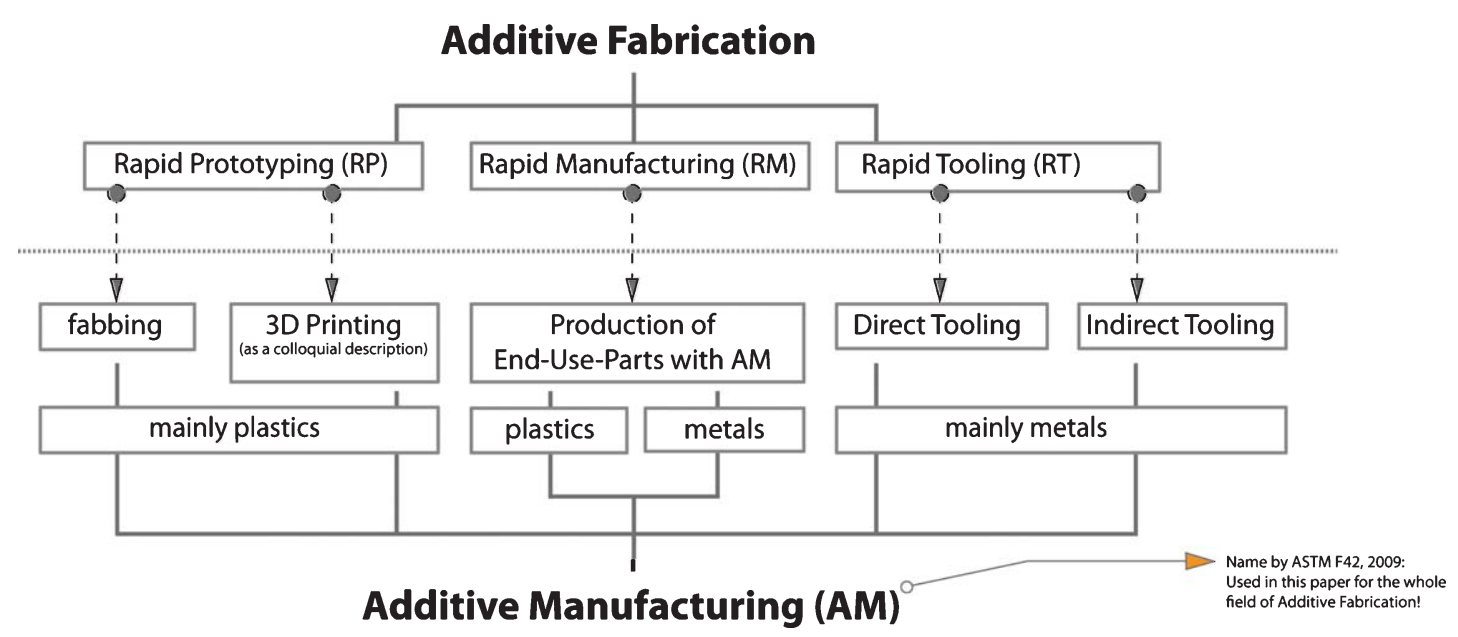

Fig. 1. Overview 'Additive Fabrication'; use and allocation of various terms for the different areas of the AM industry.

It can be observed that over the last decades all professional participants, that are applying AMtechnologies in R\&D or business application, have fostered the former niche production processes into a new industrial field of production.

Changed prerequisites in the AM industry led to more awareness and acceptance over the last years. More and more people got aware of the available AM technologies and started to use them as an additional tool in industrial design, mechanical engineering and others. Also a big part of the newly developing applications and ideas come from the 'Do-It-Yourself' part of the industry. Tinkerers across the globe are developing open source desktop 3D printers - so called 'fabbers' (Burns, 1999-2003). On the one hand this opens decentralised manufacturing of individualised products to the people, on the other hand this makes AM technologies affordable for teaching institutions and laymen. This development supported to spread the idea of AM further, opening new markets, giving new ideas.

Parallel to the development of the AM technologies, also the so called 'third industrial revolution' happened over these last three decades (Whadhock, 2012). The first industrial revolution changed the British textile industry with automated weaving looms in the 18th century. It started a fast pace of technical innovation to follow up, changing the society from agricultural to industrial. The second 'Industrial Revolution' was started by the invention of the production line in the automotive industry in the United States of America in the 19th century by Henry Ford. In his article about the digital revolution Whadhock brings up keywords like 'social manufacturing', and predicts that "as manufacturing goes digital, a third great change is now gathering pace. It will allow things to be made economically in much smaller numbers, more flexibly and with a much lower input of labor, thanks to new materials, completely new processes such as 3D printing, easy-to-use robots and 
new collaborative manufacturing services available online. The wheel is almost coming full circle, turning away from mass manufacturing and towards much more individualized production. And that in turn could bring some of the jobs back to rich countries that long ago lost them to the emerging world."

This strive for customisation is definitely a growing demand in today's' societies, but it also reflects back to all fields of social live (Whadhock, 2012). Social Media, highly individualised live designs, more and more locally detached and independent work spaces, worldwide available cloud computing, highly infiltration of society with digital gadgets, digital tools and digital worlds lead to a higher demand for individualisation in all aspects of life. While the first and second industrial revolution aimed toward more and more repetitive processes in production and assembly, today's products and everyday items become more and more individualised. Starting with customized products - configurators in the automotive industry (VolkswagenAG, 2015), to partly individualized items 'your name on your sneakers' (Nike, 2015), to truly customized features - medical implants fitted to your body from CT digital data (Christensen, 2014), whereas so called 'Mass Customization' is already reality for a large number of available products (Piller, 2012). Adding to this aspect of today's demand for customization, AM offers the possibility of highly individualized parts at the same cost of an ordinary standard part, as with AM cost per piece is no longer linked to complexity. A straight printed cube of equal volume causes the same amount of print time, consumed material and energy involved as a highly detailed and digitally morphed structure (Sandhana, 2013).

\section{Printed building construction - sample facades}

On this background, it can be expected that facade technology and facade construction will change with the application of Additive Manufacturing. The building envelope is - due to functionality and industrialisation of the industry - one of the most challenging parts of the building. It has a multitude of expected performances, it separates inside from outside and gives the face to the building. For the one-of-a-kind architectural designs, the facade is the suitable part of building construction to represent the design intent of the customer, architect and user. But in building construction also specific requirements have to be met with the applied products. Aspects that are related to every building activity have to be addressed and to be met: legal aspects like building codes and liabilities or economical aspects like market demand and market acceptance. All aspects are regulated by the building authorities; it is therefore a bigger approach to bring AM to a certified production process in building construction.

But as the market is demanding for bespoke solutions, AM is a tool at hands that meets the requirements of low batch production, perfectly matching the one-of-a-kind designs in architecture.

Already today companies from the facade Industry are testing the applicability of AM for their products, like in the aviation industry, at first for non-structural components only (cappings, end pieces, etc.), but with further development of material properties in the close future for structural applications. In this context also batch size is one aspect of the decision: investment for tooling and production vs. needed number of parts and fast time-to-market circuits.

\section{Freeform geometries}

One example of an innovative application of the new technologies is the demand of freeform geometries by the architect. There are different strategies to deal with freeform: 
- true freeform, that means doubly curved surfaces, that are very difficult to produce in most of the building construction materials;

- tessellated surfaces, where an approximation can be made between true freeform and ruled surfaces, ending in an almost freeform surface;

- faceted surfaces, where from the beginning the free form is broken down into straight members, that allow for standard production.

There are products that allow for 'true freeform' (double curved surfaces), like fabrics and membranes. But most of the time they are not meeting the building construction requirements and also follow structural and geometric rules that disturb the pure freeform approach. Therefore other solutions are needed. Some producers start to open their production toward freeform. E.g. Rieder concrete is investigating into freeform facade panels (Rieder, 2013). Also there have been approaches with free-formed aluminium extrusion profiles for stick system facades. But how to deal with the doubly curved surfaces that will appear for the infill panels? How can the glazing be realized? This leads to bended glass, or to new ways of producing those doubly curved elements with AM technologies: for example with 3D printed glass - 'Direct Glass Fabrication' (Rammig, 2010) (see Fig. 2), or with freeform dome structures from clay or concrete - 'Contour Crafting' (Khoshnevis, 2006) (see Fig. 3). There are ideas at hands, and they can support the further development of additive processes from cooperative research, the specialist's input and the academic approach.

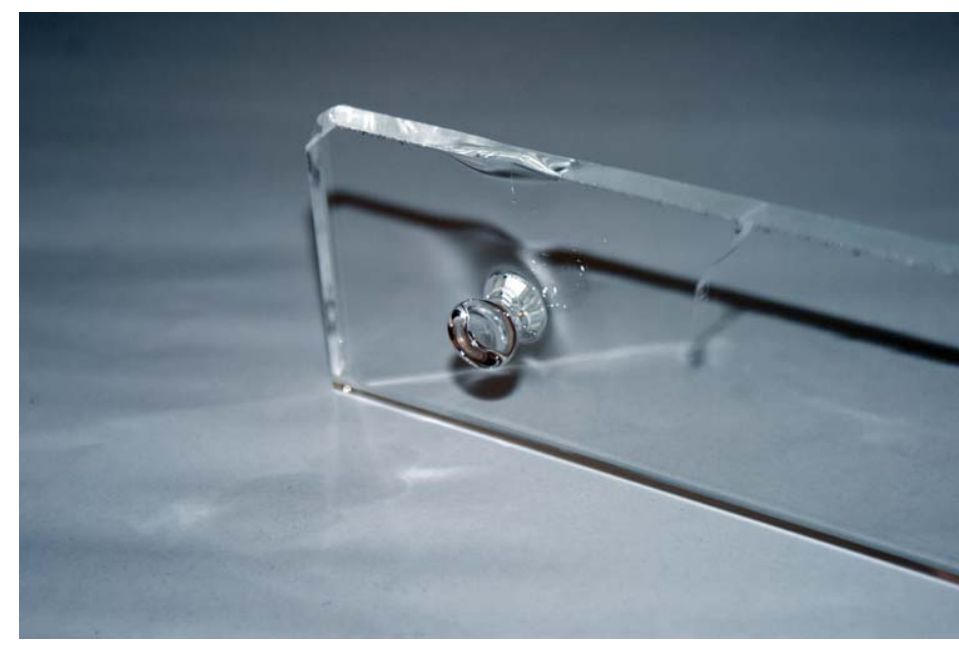

Fig. 2. Prototype of point fixation made with Direct Glass Fabrication (DGF).

\section{3D system offerings for facades?}

In the near future solutions for complex geometries with the safety of a system offering may be hybrid systems that combine mass-produced and mass-customized parts in one solution. Looking at it, this seems to be a contradiction, because system offerings and bespoke solutions do not go together. But regarding the background of the long-term experienced and - maybe even more important - certified system offerings, it makes sense. To develop a facade for the western market without coming back to the certified and tested system offerings is economically almost impossible. Therefore it is logical to implement new technologies into the production line, and achieve more satisfying results for the architect and customer. At the end one-of-a-kind projects will have the individualized look they need, but also have the reliable functioning details regarding building physics and performance. 


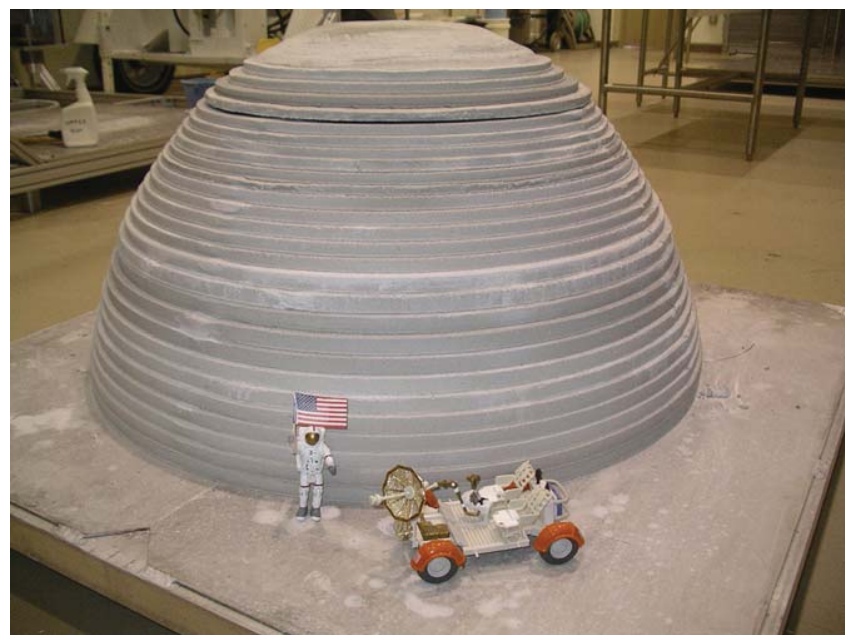

Fig. 3. Scaled prototype of lunar dome structure printed with Contour Crafting (CC). Credits Behrokh Khoshnevis, University of Southern California, USA.

\subsection{Additive fabrication}

As a new part of the production chain, additive fabrication will change the way we design and produce as well as how we handle consumer goods and our built environment. In order to make these changes tangible for facade construction, case studies with realistic application concepts from the facade technology were carried out. Initially it was difficult to identify such concrete applications for AM, due to our habit to think subtractive rather than purely functional. However, it did lead to an intensive examination of the technologies and to defined approaches and results. Relevant aspects of the studies include material consumption and assembly as well as component performance in the facade system, amongst others.

The development of AM is still in the beginning stage; however, AM technologies offer the potential to lastingly change design and construction methods. The change in our way of thinking has long begun: File-to-factory, Building Integrated Modelling (BIM) and digital materials are the key words in this on-going discussion in the day and age of parametric design and construction called 'the age of Grashopper' (Davidson, 2012). Further development of the new technologies is progressing rapidly; it is foreseeable that AM will be intuitively and naturally used in the future and, thus, will find an application in many new areas - even in the somewhat conservative building sector (Strauß, 2008).

The authors were involved in an industry-supported research between the University of Applied Sciences - Hochschule OWL, Detmold, Germany and Kawneer-Alcoa that focused on the potential of Additive Manufacturing for facade construction. This paper will not give specific technical background information on the technology, but refers to the previously published papers and books of the writers about the topic (Knaack, 2010; Strauß, 2013).

\subsection{The nematox facade node}

The Nematox facade node is the result of a cooperative research between industry and academics. The project was carried out from 2008 to 2010. It shows that it takes a while to come from initial ideas to a reliable invention. In this case the conducted research was finalized with the presentation 
of the Nematox facade node (see Figs. 4 and 5). It presents the capability of AM technologies to be combined with facade system offerings, and as a result it could offer a new step toward freeform geometry in facades (Strauß, 2010).

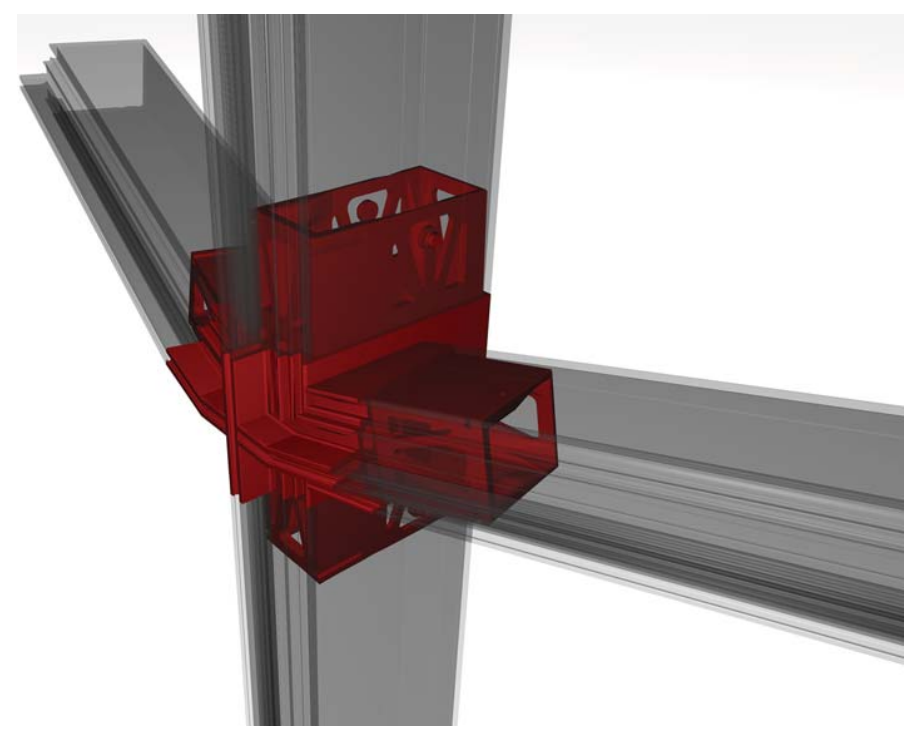

Fig. 4. Rendering of Nematox facade node.

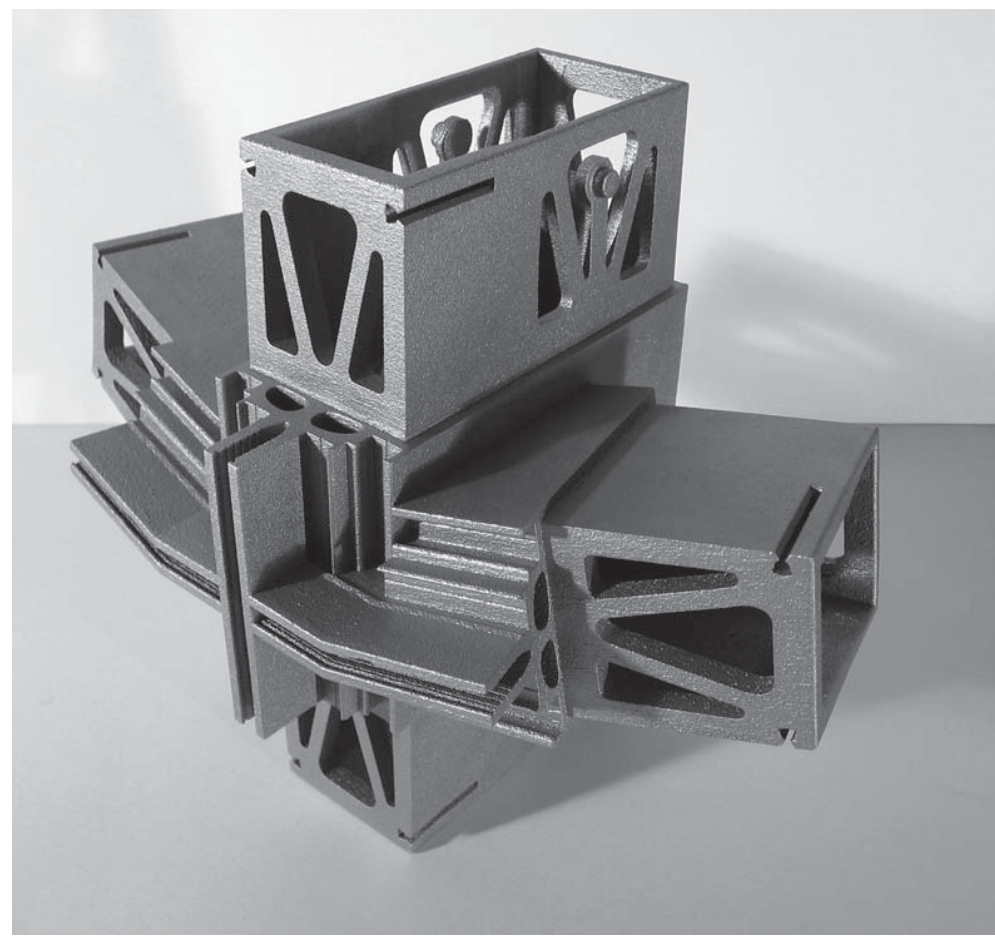

Fig. 5. Aluminium printed mock-up of Nematox facade node. 
After the completion of the research project, the company took almost three years to pick the idea back up. But looking at it today, the time passed added to the realistic approach of the initial development. Over these last years a lot of progress was made within the AM technologies for 'Direct Metal Fabrication'. Production times were reduced, quality assessment was enhanced and prices for the AM systems and materials dropped significantly.

The reason for Kawneer-Alcoa to come back to the idea lies between 'artistic architectural ideas' and 'industrial research': today Alcoa clearly envisions a market for individualized facades, digital planning processes and tools. Also AM offers a product enhancement within each new project; as the parts are virtually planned and designed on the computer, no extra tooling or expensive machinery is needed. The lead times from design to production are drastically reduced by implementing AM into this production chain. No tooling costs or tooling times need to be accounted for. All this is in favour for digital production of smart, neuralgic parts in a free-formed facade.

Klaus-Martin Hees (Research Director Europe, Kawneer-Alcoa): “Three years ago, we were missing the matching marketing strategy for the Nematox node. Therefore the topic was only theoretically looked at. In the meantime the market and the requirements hereof have changed constantly. There is a trend toward more and more complex constructions with even shorter lead times for their realisation. On this background we have re-launched the Nematox project in 2013 [...]" (Hees, 2013).

Even in 2016, the addendum 'rapid' is a relative term in conjunction with AM methods, because an actual production process may take up to several days. However, the equipment development has reached a stage where the combination of processing speed and material properties does achieve 'fast' effective manufacturing rates when compared to traditional methods. This comparison takes into consideration the time it takes to produce a conventional tool set (e.g. for injection moulding) for traditional methods. But speed is not the most important aspect when evaluating AM Technologies. The main advantage lies in the great freedom of form compared to traditional methods. When transferring this existing new technology into real facade projects, the innovative potential will face the budget reality of the future projects. Still the author strongly believes in the potential of Additive Manufacturing for facade construction. The Nematox facade node is the proof of concept from research cooperation between building industry and academic research and adds extra value to well-known applications (Strauß, 2013).

There are already prototypes of 'printed' houses and building construction components for smaller huts and pavilions existing, that aim directly for the built environment (Sandhana, 2013). One example is the 'KamerMaker' in Amsterdam as a direct applied architectural approach - a printed canal house (DUSarchitects, 2015) (see Fig. 6). Life size printed parts and components in materials that suit building construction come to the fore. Concrete building structures are the result of research conducted at universities and institutions; here Contour Crafting by Behrokh Khoshnevis is a vision with a well known material in building construction: concrete. (Khoshnevis, 2006) (Fig. 7: CC-concrete part with nozzle). All examples show the potential AM has for building construction - all in completely different ways, but all fostering the great advantage of layer wise production.

According to a survey conducted by the German research institute DMRC, most of the applications in the research sector aim toward 'Direct Manufacturing' as the major application of AM ( $\sim 80 \%)$. Still followed by 'Rapid Prototyping' ( 66\%), 'Rapid Tooling' ( 33\%), and 'other applications' ( $\sim 19 \%)$. Whereas the numbers account over a total of $100 \%$, as numerous activities could have been chosen by the surveys' participant. Nevertheless, it shows exactly the shift in the professional field of AM, from pure Rapid Prototyping to an end-use application of ready-to-use parts (Gausemeier, 2013). 


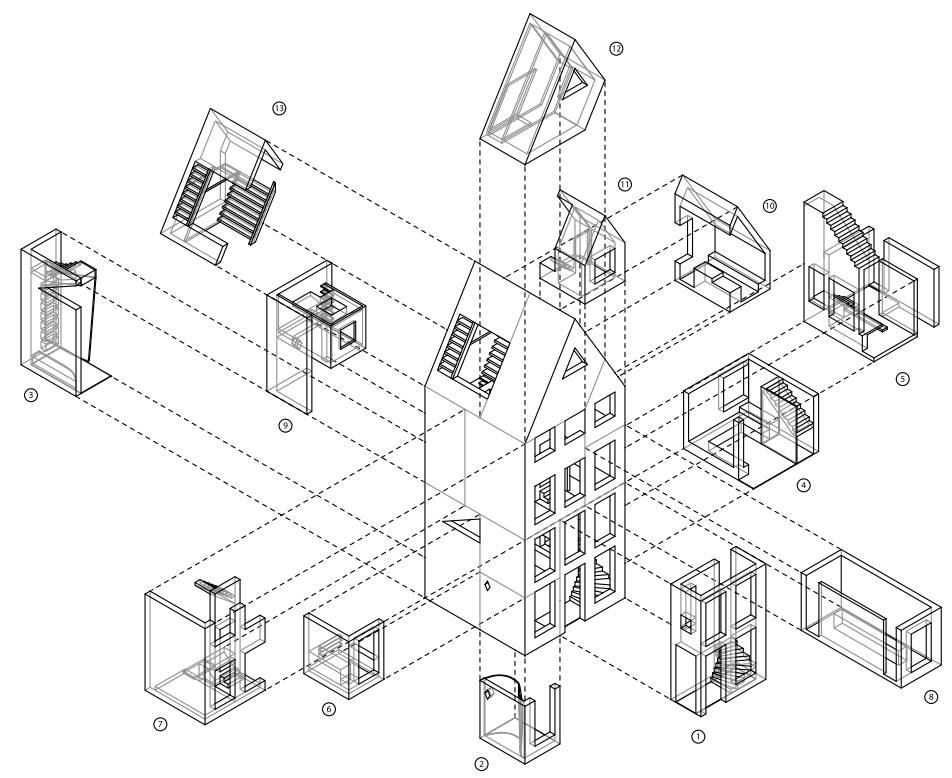

Fig. 6. Axonometric view of the construction parts being printed by the KamerMaker (ba DUSarchitects).

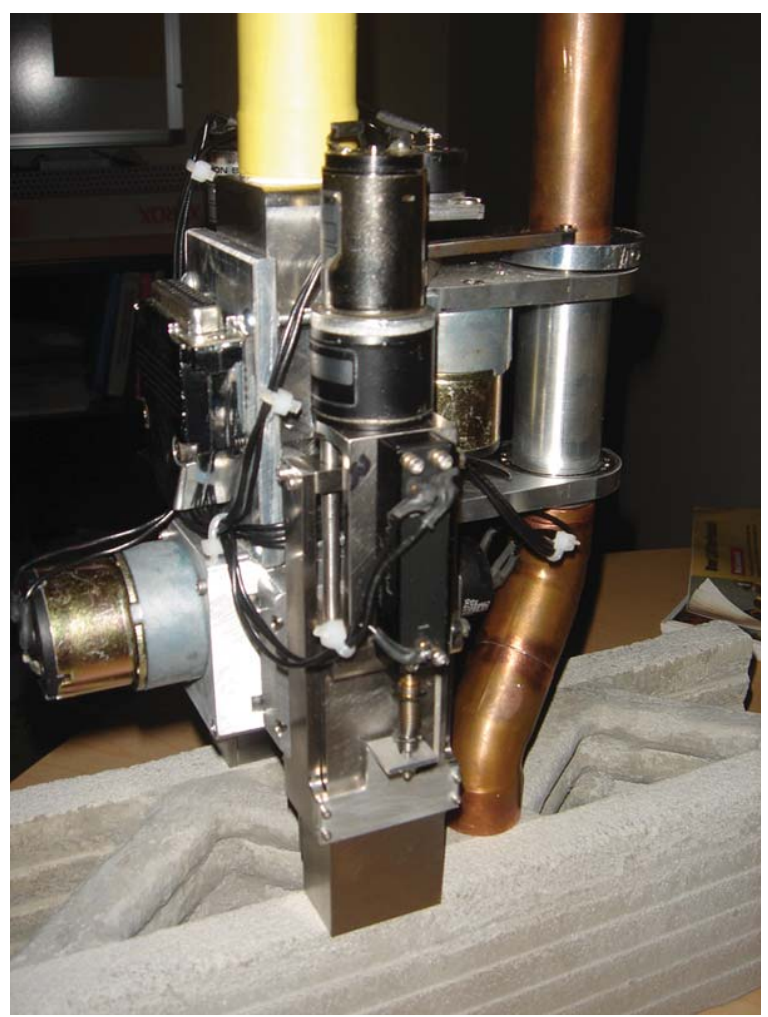

Fig. 7. ContourCrafting-concrete part (CC) with printing nozzle. Credits Behrokh Khoshnevis, University of Southern California, USA. 
The development of AM compliant applications will also bring forth new materials to facade technology that will maybe be more suitable to manufacturing as well as for the required functions than conventional materials. Materials do not matter in the first place, but can also lead to new applications - if we think of the massive amount of iron-mongery that is needed to make a functional opening casement: what if the hinges and fittings would be incorporated and 'digitally' mounted to the mullions in one corporate material? The healthy, naïve view of the architect helps engineers and constructors to lift, if not take off entirely, blinkers that protect from the unknown. And now material scientists even started to add a new dimension to 3D printing, as the technology itself goes on: introducing now the fourth dimension to 3D printing - called 4D printing. Researchers at Pittsburgh University now investigate into additional values from smart materials incorporated into AM parts via stimuli-responsive components in AM materials (MaterialsViews, 2013).

"Dare to be Naive", as Buckminster Fuller said, could be a leading thought for all innovation in the building sector. The intensified normative regulation, the higher and higher requirements as a result of building codes and guidelines limit more and more the optimistic and daring approach that architectural engineering once had. Definitely facades face higher and higher demands regarding design intent (geometry) and performance (building physics, technical fit out, services). The building envelope therefore has a high potential for innovation. This starts at a very primary construction of a house and facade, and ends in Mike Davies' 'Polyvalent Wall' (Davies, 1981).

\section{Outlook}

Even after three decades since its invention, AM is still under development. Many different factors add up to the full picture of its eruptive potential for the known production processes. Application in building technology, especially in the building envelope has great potential. The 'rapid' development over the last ten years gives hope to keep the pace as in the personal computer market. Indicators are:

- Larger building envelopes/chambers: raised every year, the biggest step was undertaken by Voxeljet, Germany, where the biggest available building chamber now offers a size of $4000 \times 2000 \times 1000 \mathrm{~mm}$ (Voxeljet, 2015). This offers the possibility to print live size components for building construction - e.g. steel constructions, nodal points for large-scale structures.

- Faster production times: the speed can be enhanced with various measurements within the AM processes; SLM solutions, Germany, for example came up with a combination of multiple laser sources in one machining centre. This is possible, as cost for industrial lasers dropped significantly over the last years. This leads to faster production times and higher output, and reaches semi-industrial production batch sizes, and was not expected five years ago.

- Advanced CAD-CAM interfaces: more and more cooperative software solutions, with more and more intuitive surfaces and functions, alternative file formats and other changes move AM toward 'digital production'. A deeper understanding of complex planning processes and the right tools at hands to produce digital designs with digital tools further incorporates new technologies into existing production processes. One tool is $A M$, other tools are high speed milling, water jet cutting, CNC saws, CNC milling centres, and many more. Hybrid technology application is the desirable application of AM.

Architectural and engineering vision for AM in the building industry is the smart combination and hybrid solution of well known standards and of the bespoke and tailored individual components. This is what makes the difference between mass produced and mass customized, regarding the need for reliable construction - safe with respect to the lives that are under risk in our built 
environment -, but also regarding the demanding requirements of all ecological aspects that are related to every building activity.

AM is one eruptive new technology within the digital revolution. After its 25 years of infancy it now faces reality and is entering the architectural market. It has the potential to change the way we design, construct and produce. To start, for example, with a very delicate single piece of a holistic facade approach at first will be an adequate beginning. And it will be the beginning to open new ways in facade building.

\section{Summary}

This article shows the potential of Additive Manufacturing (AM) for the future development of building envelopes: AM will change the way of designing facades, how we engineer and produce them. New technologies offer one possible way to do so. They open new approaches in designing, producing and processing building construction and facades.

AM offers the opportunity to manufacture facades 'just in time'. It is no longer necessary to store or produce large numbers of parts in advance. Initial investment for tooling can be avoided, as design improvements can be realized within the dataset of the AM part. The parts performance can be re-interpreted based on the demands within the system, and not based on the limitations of conventional manufacturing. This may lead toward customized and enhanced performance.

The basic principle of AM opens a new world of engineering, no matter what applications can be found: to 'design for function' rather to 'design for production' turns our way of engineering of the last century upside down.

AM will never replace established production processes but rather complement them where this seems practical. AM is not the proverbial Swiss-army knife that can resolve all of today's facade issues! But it is a tool that might be able to close another link in the 'file-to-factory chain'. AM allows us a better, more precise and safer realization of today's predominantly free designs that are based on the algorithms of the available software. With such extraordinary building projects, the digital production of neuralgic system components will become reality in the near future today, an AM Envelope is close at hand. Still, 'printing' entire buildings lies in the far future; for a long time human skill and craftsmanship will be needed on the construction site combined with high-tech tools to translate the designers' visions into reality.

\section{References}

Burns, M. (1999-2003). fabbers.com, 2012, from http://www.ennex.com/\%7Efabbers/

Christensen, A. (2014). Changing the game in Healthcare. TCT Magazin, 82.

Davidson, S. (2012). Grasshopper - Generative Modeling for Rhino, 2012, from http://www.grasshopper3d.com/

Davies, M. (1981). A Wall For All Seasons. RIBA Journal, 2(88).

DUSarchitects (2015). 3D Print Canal House. Retrieved 31.03.2015, 2015, from

http://3dprintcanalhouse.com/kamermaker-1

Gausemeier, J. (2013). Evaluation of the expert survey on the Future Relevance of Additive Manufacturing Research. Paderborn, Germany: DMRC, Heinz Nixdorf Institute, University of Paderborn.

Hees, K.-M. (2013, 20 September 2013). [Research Director Europe. Kawneer-Alcoa].

Hopkinson, N., Hague, R. J. M., \& Dickens, P. M. (2006). Rapid Manufacturing. An Industrial Revolution for the Digital Age. Chichester, England: John Wiley and Sons, Ltd.

Khoshnevis, B. (2006). Contour Crafting, from http://www.contourcrafting.org/

MaterialsViews. (2013). Entering an new dimension: 4-D printing. Materials Views Newsletter Retrieved October, 2013, from http://www.materialsviews.com/entering-a-new-dimension-4-d-printing/

Nike (2015). nikeid. Retrieved 31.03.2015, 2015, from http://www.nike.com/de/de_de/c/nikeid

Piller, F. T. (2012). Mass Customization \& Open Innovation - A Blog by Frank T. Piller. Retrieved April 2012, from http://mass-customization.de/ 
Rammig, L. (2010). Direct Glass Fabrication - New Applications of glass with additive processes. M.Eng. Masterthesis, Hochschule OWL - University of Applied Sciences, Detmold.

Rieder, A. (2013). fibreC - 3D fassade. Retrieved September 2013, 2013, from http://www.rieder.cc/at/de/main/referenzen/reference/19/

Sandhana, L. (2015). The room with 260 million surfaces: 3D printed architecture is here. gizmag online newsletter. Retrieved from www.gizmag.com website: http://www.gizmag.com/swiss-architects-3dprint-a-room/29299/

Strauß, H. (2008). Funktionales Konstruieren - Einfluss additiver Verfahren auf Baukonstruktion und Architektur. Dipl.-Ing., Hochschule OWL, Detmold.

Strauß, H. (2010). AM Facades - Influence of additive processes on the development of facade constructions. Final Report of research project. Hochschule OWL - University of Applied Sciences. Detmold.

Strauß, H. (2013). AM Envelope - The potential of Additive Manufacturing for facade construction. Delft University of Technology, Delft. $(A B+E, 01 / 2013)$

Knaack, U, Bilow, M., Strauß, H. (2010). Rapids - Layered Fabrication Technologies for Facades and Building Construction (Imagine 04). Rotterdam: 010 Publishers.

VolkswagenAG. (2015). Konfigurator von Volkswagen.de. Retrieved 31.03.2015, from http://app.volkswagen.de/ihdcc/de/configurator.html

Voxeljet. (2015). VX4000: Das großformatige 3D-Drucksystem. Retrieved 31.03.2015, from http://www.voxeljet.de/systems/vx4000/

Whadhock, I. (2012). A third industrial revolution. The Economist. Retrieved from http://www.economist.com/node/21552901

Woodcock, J. (2011). Living in a (Multi) Material World - Object Focus on Democratizing Multi-Materials Process and new functional materials. tct magazin. 